By: Timothy D. Johnston \& Gilbert Gottlieb

Johnston, T. D., \& Gottlieb, G. 1981. Development of visual species identification in ducklings: What is the role of imprinting? Animal Behaviour, 29(4):1082-1099.

****Reprinted with permission. No further reproduction is authorized without written permission from Elsevier. This version of the document is not the version of record. Figures and/or pictures may be missing from this format of the document.***

**** Note: $\underline{\text { http://www.elsevier.com/ }}$

Abstract:

The phenomenon of imprinting (a rapid form of exposure learning) is widely presumed to underlie the formation of normal, species-typical social preferences in precocial birds. To determine whether this is in fact the case, 24-h-old domestic and semi-wild mallard ducklings (Anas platyrhynchos) were allowed to follow a stuffed hen of one of three sympatric waterfowl species for $20 \mathrm{~min}$. The models used were mallard, redhead (Aythya americana), and pintail (Anas acuta) hens. When later tested for their preference for the familiar hen in simultaneous choice tests with one of the other two stuffed models, only those birds trained with the Mallard and tested with the Mallard and Pintail models (designated the Mallard versus Pintail group) showed a preference for the familiar model. (That preference was shown by both domestic and semi-wild ducklings.) In none of the other three groups (Mallard versus Redhead, Redhead versus Mallard, and Pintail versus Mallard) was the imprinting procedure effective in producing a preference for the familiar model. When other ducklings were similarly trained with either the Mallard model, a red-and-white-striped box, or a green styrofoam ball, a preference for the familiar model was found in all four groups (.Mallard versus Red Box, Red Box versus Mallard, Red Box versus Green Ball, and Green Ball versus Red Box). Increasing the length of the training period from 20 min to $2 \mathrm{~h}$ and to $24 \mathrm{~h}$ did not produce a preference for the familiar Mallard over the unfamiliar Redhead. These results raise some doubt that imprinting as currently conceived is the behavioural mechanism of visual species identification as it occurs in nature.

Article:

The concept of imprinting has been one of the most prominent theoretical achievements in the study of behavioural development since it was first given a wide audience by Lorenz (1935/1937), following the earlier and less-well-known studies of Spalding (1873) and Heinroth (1911). Lorenz used the term 'Prägung' (translated as 'imprinting') to denote a rapid and apparently irreversible process whereby the young of certain precocial birds (notably geese, ducks, and chickens) acquire social preferences for the first object they encounter shortly after hatching. Under normal circumstances this object would be their mother, and Lorenz proposed that imprinting is the mechanism whereby these animals learn to identify the distinguishing visual characteristics of their species and subsequently direct affiliative and sexual behaviour only toward conspecific individuals. Lorenz (1935/1937) postulated that parallel, independent processes of this kind are involved in the formation of different types of social attachments, so that the young bird acquires a functionally distinct social companion ('Kumpan') for each of its various social activities. Subsequent research has focused on two such processes: the development of filial and of sexual attachments.

It is important to realize that there are two quite distinct elements that must be distinguished in any discussion of imprinting. The first is a behavioural problem that the young bird must solve in the course of its development, -namely that of directing social behaviour only towards members of its own species. The Second is a proposed solution to that problem, which, in the case at hand, is the process of imprinting as described by Lorenz and amended by many subsequent investigators (e.g. Hess 1973; Sluckin 1973; Bateson 1966, 1979). Most of the work in this field over the past 45 years has concerned the characteristics of the imprinting process; 
for example, its irreversibility and the existence and extent of a sensitive period when attachments may be formed most readily. By contrast, rather little attention has been paid to the behavioural problem of species identification and the extent to which imprinting may be involved in its solution under natural circumstances. In this paper our concern is with the latter of these two questions, rather than with the characteristics of the imprinting process itself.

In a typical imprinting experiment, a young precocial bird (usually a domestic chick or duckling) is briefly exposed to an object, the imprinting object, between 12 and $30 \mathrm{~h}$ after hatching. Sometime later, usually after another 24 or $48 \mathrm{~h}$, the bird is tested to see whether it has formed an attachment to the imprinting object, as shown by a preference for the object in choice tests. Control procedures are employed to determine whether the bird has any naive preference for the object, in the absence of previous exposure to it.

The variety of objects to which precocial birds may be imprinted in this way is very great, a fact that has given wide popular appeal to the imprinting experiment: most people are familiar with the spectacle of goslings in close pursuit of Konrad Lorenz, whom they treat as they would their mother under normal circumstances. A large number of experiments have shown moving objects (such as coloured balls and boxes) and flashing lights to be especially effective imprinting objects, and stimuli of this kind have become the staple 'mother surrogates' of most recent studies of imprinting. However, the use of such highly artificial objects to study the development of social attachments in precocial birds raises the question of whether the process that is being studied in such experiments is the same as that by which normal, species-typical preferences are formed under natural circumstances. It is obvious that young birds do not have to distinguish among differently coloured flashing lights, red cylinders and green cubes, or any of the other objects that are typically employed in laboratory studies of imprinting. What they may have to do is to distinguish members of their own species from those of other sympatric species, especially those with habits sufficiently similar to their own that they will frequently come into contact with them. In the case of ducklings, for example, that would mean being able to distinguish conspecifics from members of sympatric species of waterfowl.

The use of artificial objects for the study of imprinting can be justified on the grounds that the differences between the objects employed are broadly similar to those that exist between biological species (that is, visual differences of colour and form), and that by using artificial objects the experimenter gains control over these differences and can manipulate them systematically. However, it is a tenuous assumption that the discriminative visual features normally involved in the acquisition of social preferences are adequately represented among the objects typically employed, in laboratory studies of imprinting. It has been repeatedly pointed out, by Brunswik (1952), Gibson (1966, 1979), Gottlieb (1976), Bronfenbrenner (1977, 1979), McCall (1977), and Miller (1977a), among others, that the most carefully controlled experiment is of dubious significance to an understanding of natural behavioural processes unless it can be shown that control is being exercised over relevant dimensions of the subject's experience. It remains an open question whether the kinds of variation among objects that have been employed in imprinting experiments are relevant to the problem of species identification under natural circumstances; and it comes as something of a surprise that, after 45 years of imprinting research, that question remains unanswered.

The experiments reported in this paper were undertaken to determine the extent to which the development of social preferences by domestic mallard ducklings (Anas platyrhynchos) among biologically arbitrary objects is an adequate model of the development of such preferences among more biologically relevant objects. To investigate this question, we employed an experimental design that is representative of previous studies of imprinting but instead of using artificial objects, we used natural stuffed models of various species of waterfowl.

\section{General Method}

\section{Subjects}

Both Peking ducklings, a highly domesticated strain of the mallard duck (Atlas platyrhynchos L.), and semiwild mallard ducklings, the offspring of matings between wild male and game-farm female mallards, were used 
as subjects. The Peking ducklings were hatched from fertile, unincubated eggs received weekly from a commercial supplier. The semi-wild mallard ducklings were hatched from fertile, unincubated eggs supplied by the Max McGraw Wildlife Foundation of Dundee, Illinois. On arrival, the eggs were washed and stored in a refrigerator at $9 \mathrm{C}$ for $24 \mathrm{~h}$ to permit convenient scheduling of hatching dates. The eggs were set in a Petersime Model IV incubator, which was maintained at $37.8 \mathrm{C}( \pm 0.25 \mathrm{C})$ and 65 to $74 \%$ relative humidity, and were automatically turned every $6 \mathrm{~h}$. After 23 days of incubation, the eggs were transferred to hatching trays in the bottom of the incubator. The hatching eggs were checked frequently and the time of hatching of each duckling recorded to the nearest half-hour. Hatched ducklings were placed in individual cardboard or opaque plastic boxes $\left(10 \mathrm{~cm}^{3}\right)$ and transferred to a brooder, maintained at $31 \mathrm{C}$, in which they could hear but not see other ducklings. No food or water was provided for the duration of the experiment.

The mean hatching success per batch was $83 \%(\mathrm{SD}=9.7 \%$; range $=50-97 \%)$. Only those ducklings that hatched during day 26 (Peking) or day 25 (semi-wild mallards) of incubation were used in the experiments. (By convention, day 26 of incubation begins at 26 day, $0 \mathrm{~h}$, and ends at $26 \mathrm{day}, 23 \mathrm{~h}$.) Although the incidence of between-hatch variation in behaviour, which is high in chicks, is generally insignificant in ducklings, we sought to reduce the possible influence of this factor by drawing subjects for each experimental group from several batches of eggs (mean $=3.1$ batches/group). In no case were we able to detect any influence of batch variability on our results. The number of batches/group is reported separately for each group in each experiment below.

\section{PLATE I}

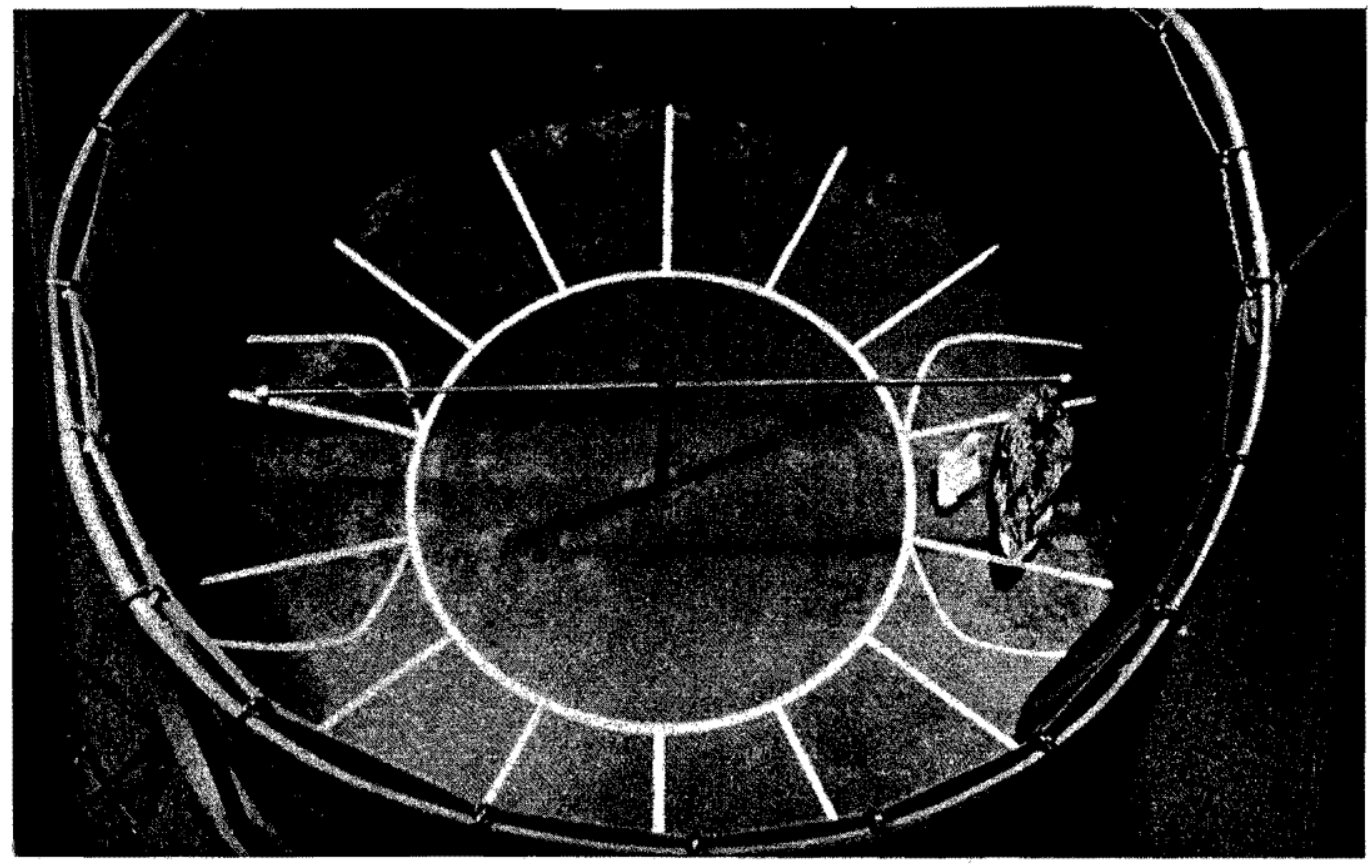

Fig. 1. The experimental apparatus as seen in the viewing mirror from the observer's station, showing a duckling approaching the Mallard model during training. During testing the other test model was suspended from the opposite end of the T-bar. The start point was the vertical white line at the top of the photograph and the model is shown in the starting position. Models moved in a counterclockwise direction. A fixed speaker was located behind the curtain in the centre of each of the two elliptical areas on the right and left.

\section{Apparatus}

All training and testing was conducted in a circular arena, $178 \mathrm{~cm}$ in diameter, surrounded by an 81-cm-high opaque black curtain that shielded the observer from the subject's view. Subjects were observed by means of two angled mirrors suspended above the arena. A photograph of the apparatus may be seen in Gottlieb (1971, Fig. 2). The inside of the arena was painted flat black with a pattern of white lines on the floor (see Fig. 1, Plate I) to facilitate the scoring of following and approach behaviour, as described below. A fine grit mixed with the paint provided a roughened surface to increase traction. In the centre of the arena was a vertical drive shaft that passed below the floor where it was connected to an electric motor geared to rotate the shaft at a constant speed of $1.2 \mathrm{rpm}$. Attached to the shaft above the floor of the arena was a T-shaped tubular suspension arm. The models were suspended from the ends of the cross-arm, and hung approximately $2 \mathrm{~cm}$ above the floor. When 
the motor was running, they moved around a circular path, $455 \mathrm{~cm}$ in circumference, at a constant speed of 9.1 $\mathrm{cm} / \mathrm{s}$. The suspension bar and the hardware associated with the models were painted flat black.

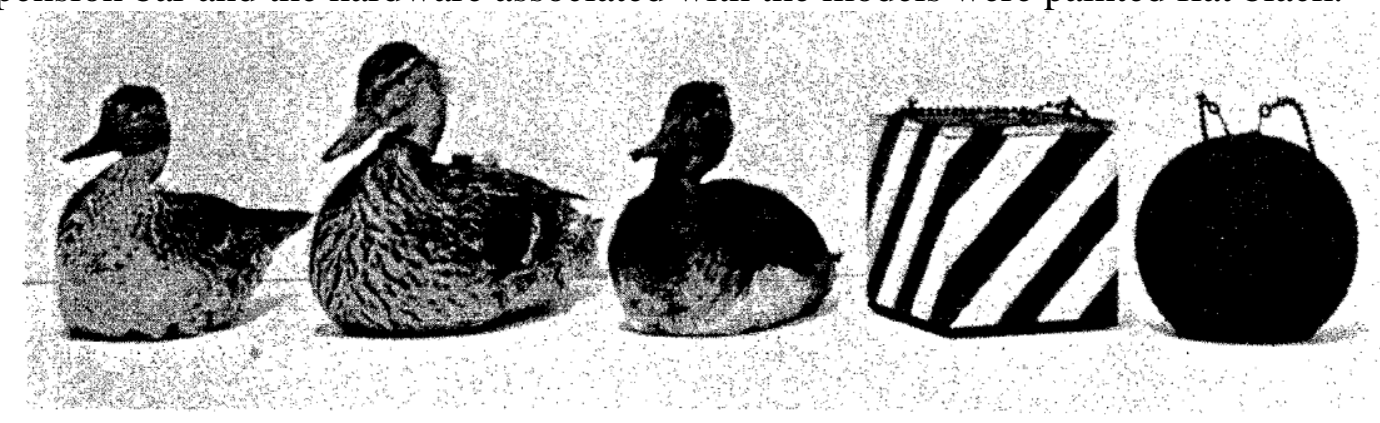

Fig, 2. The five models used in the experiments. From left to right: Pintail, Mallard, Redhead, Red Box, Green Ball. Scale shown by Green Ball (15 $\mathrm{cm}$ in diameter).

Figure 2 (Plate I) shows the five imprinting models used in this study. Three were stuffed natural models of adult female waterfowl of the following species: mallard (Anas platyrhynchos), pintail (Anas acuta), and redhead (Aythya americana). The other two were artificial models: a red-and-white diagonally striped 15-cms wooden box and a bright-green 15-cm-diameter polystyrene ball. Each model was equipped with a hidden 9$\mathrm{cm}$-diameter loudspeaker. The speaker wires ran through the tubular suspension bar to a vacuum-sealed slipring assembly underneath the arena. The external (stationary) terminals on this assembly were connected to a Revox Model A77 stereo tape recorder, allowing calls to be broadcast from the models. In addition to these moving speakers, two fixed speakers were mounted at opposite sides of the arena for use in stationary approach tests (see below).

The tape recorder and drive motor were operated by remote switches placed at the observer's station. A system of foot-operated timeclocks was used to score the latency and duration of following and approach responses, as described in detail below. The testing room was maintained at approximately $20 \mathrm{C}$ throughout the experiment.

\section{Procedures}

Training. With the exceptions described below w, a single training trial, 20 min long, was given to each subject at $24 \mathrm{~h}( \pm 6 \mathrm{~h})$ after hatching. The imprinting model was suspended from one arm of the T-bar and positioned $90^{\circ}$ to the right of the start point (see Fig. 1). During the training trial, the other end of the T-bar was always empty. At the beginning of the trial, the subject was placed at the start point and the tape recorder and drive motor turned on, so that the calling model moved toward the subject.

The call used was a natural mallard maternal assembly call (Gottlieb 1971). It consisted of a burst of 9 notes, played at a tape speed of $19 \mathrm{~cm} / \mathrm{s}$ at the normal repetition rate of 3.7 notes/s. Prior to each test session, the call was adjusted to have a peak amplitude of $70 \mathrm{~dB}$ (B weighted scale, fast response), measured at the start point. The call was played continuously throughout the training trial, with a pause of $1.5 \mathrm{~s}$ between successive bursts. The ducklings' early visual exposure to the hen, whether on the nest or during the exodus from the nest, occurs in the context of auditory exposure to her call (Miller \& Gottlieb 1978). Thus, to that extent our training procedure resembles the normal early interaction between the young and their mother. Details of that acoustical structure of the mallard maternal' assembly call are given by Miller \& Gottlieb (1978).

The latency and duration of the subject's following response were scored as follows. A 'following area' was defined, extending $12 \mathrm{~cm}$, to either side of the model and $30 \mathrm{~cm}$ behind its trailing edge. The latency of response was defined as the time from the start of the trial to the time when the subject first took three steps in the direction of movement of the model within the following area. The criterion of three steps was adopted to avoid scoring false starts. Once following began, its duration was recorded according to the following criteria: (1) more than half the subject's body had to be within the following area or, failing that, both the subject's feet had to be on the boundary of the area; (2) the subject had to be facing either toward the model or in the direction of movement of the model; (3) the subject was allowed to pause within the following area but a stationary subject was only scored as following if it had previously entered the following area itself. This last criterion was 
adopted to avoid accumulating a following score for a motionless, properly oriented subject as the model moved past it, which would have overestimated the duration of following. The position of the following area with respect to the moving model could be accurately estimated by means of the grid lines on the floor (Fig. 1). The sides of the area were defined by the inner circle and by the perimeter of the arena, respectively; the radial lines (spaced $30 \mathrm{~cm}$ apart at their midpoints) defined the successive positions of the trailing edge of the area. (It should be pointed out that the following area comprised less than $2 \%$ of the total area of the arena, so that our following scores were based on very strict criteria.) At the end of the training trial, the subject was removed from the arena, placed in its box, and returned to the brooder.

Any subject that failed to accumulate at least $11 \mathrm{~s}$ of following during the training trial was considered a nonfollower and discarded. The percentage of birds that followed in each experimental group is given separately for each experiment below; typically it was about $95 \%$. Occasionally, subjects fell on their backs or rode on top of the model; any subject that accumulated more than $4 \mathrm{~mm}$ on its back or riding on the model (combined) was discarded and such subjects were not included in the calculations of percentage of subjects following. Crippled subjects, which were unable to locomote properly, were similarly discarded. Fewer than 5\% of the subjects were discarded for these reasons.

Testing. Two test trials, each $10 \mathrm{~min}$ long, were given to each subject, one at $48 \mathrm{~h}( \pm 6 \mathrm{~h})$ and one at $60 \mathrm{~h}( \pm 6 \mathrm{~h})$ after hatching, to assess each subject's preference for the training (imprinting) model, in these trials, the training model was paired with one of the other test models, which was suspended from the other end of the T-bar. At the start of each test trial, the subject was placed at the start point with the two models $90^{\circ}$ to the right and left, respectively. The starting positions of the models were counterbalanced across subjects and alternated between trials for each subject. During the test trials, both models were silent so as to permit an assessment of the subjects' visual preferences. Latency and duration of following each model were recorded as in the training trial. Between trials, the subject was placed in its box and returned to the brooder.

Naive preference tests. For some of the pairs of models (see below), untrained subjects were tested to determine whether any naive preferences existed. Each subject was given only one 10-min test, at either $24 \mathrm{~h}$ or $48 \mathrm{~h}( \pm 6 \mathrm{~h})$ after hatching. The two models were suspended from opposite ends of the T-bar, one $90^{\circ}$ to the left, the other $90^{\circ}$ to the right of the start point, both facing toward the start point. The models remained stationary throughout the test. Identical recordings of the mallard maternal call were broadcast through the fixed speakers mounted in the wall adjacent to each model, in a partly overlapping fashion: the last three notes of the call from one speaker overlapped the first three notes of the call from the other speaker, after which there was a 1-s pause before the onset of the next pair of calls, Previous research has shown this procedure to be most effective in producing a high rate of responding in simultaneous choice tests. The left/right placement of the models and the order of call onset (whether first or second in the overlapping pairs) were counterbalanced across subjects to control for possible effects of position or onset preferences. Fixed speakers were used to avoid the slight differences in sound reproduction resulting from differences in resonant properties among the various models.

At the beginning of each trial, the subject was placed at the start point and the tape recorder turned on. Latency and duration of approach to each model were scored with reference to an elliptical 'approach area' adjacent to each speaker (see Fig. 1). An approach score was accumulated whenever the subject had more than half its body within the approach area or, failing that, had both feet in contact within the boundary line defining the area. Latency of approach was recorded as the time from the start of the trial to the time when the approach criterion was first satisfied.

Data analysis. For each of the experimental groups, statistical tests were used to answer two questions: (1) Did the choice tests reveal a preference for one or the other model? (2) Where no such group preference was revealed was there a tendency, among those subjects displaying individual preferences, to approach or follow one or the other preferred model more quickly, or for longer? In groups that provided a negative answer to the first question, a positive answer to the second question would indicate that the subjects did indeed respond 
differently to the two models, even though this difference was not revealed as a significant preference for one model in the group as a whole.

The preference of each subject was determined from its duration of following (or approach) scores in the choice tests. A score of less than $11 \mathrm{~s}$ was discarded and replaced by a score of zero, to avoid scoring accidental responses as the subject wandered around the test arena. A preference was recorded if the subject's duration score for a model was more than twice that for the other model. The significance of the preference shown by a group was tested by the binomial test. Subjects that accumulated scores for both models but that did not meet the criterion for a preference were recorded as responding to both models; those that did not accumulate a score of at least $11 \mathrm{~s}$ for either model were recorded as responding to neither.

A further measure of group preference was obtained by evaluating differences between the latency and duration scores of the subjects' response to each model, by means of the Wilcoxon test. For the purposes of this analysis, subjects that did not respond to one or both models in a test were assigned a duration score of zero and a latency score of $600 \mathrm{~s}$ (the length of the test) for the model(s) to which they did not respond.

To answer the second question posed above, both the latency and duration scores (to the preferred model) of subjects that preferred one model on a test were compared with those of subjects that preferred the other model, by means of the Mann-Whitney $U$ test. In fact, in none of the experiments did this test reveal any significant differences in latency or duration scores.

As noted above, subjects in the imprinting groups were each tested twice following training, and group preference data are reported below for both tests. Since no significant differences were found in group performances between the first and second tests, the results of Wilcoxon and Mann-Whitney $U$ tests are reported for the first test (at $48 \mathrm{~h}$ ) only. The use of a test/re-test procedure also allowed us to examine the stability of preferences shown by individual subjects (see Table III), using a $\chi^{2}$-test to evaluate the null hypothesis that there is no stability of individual preference between tests (i.e. that each subject chooses independently on each test). All significance levels reported are two-tailed.

Data on hatching, ages, and training performance. For each of the experiments reported below, the following data are presented in a separate table: group size, number of batches/group, percentage following during training. length of incubation (mean $\pm \mathrm{SD}$ ), post-hatch and developmental age at training and at testing (mean+SD), and latency and duration of following during training (median and interquartile range). Throughout the paper, these data are referred to as 'hatch, age, and training data'.

Table I. Hatch, Age, and Training Data for Peking Subjects Given 20 min Training with Natural Models in Experiment 1

\begin{tabular}{|c|c|c|c|c|c|c|c|c|c|c|c|c|}
\hline \multirow{2}{*}{ مُ } & \multirow{2}{*}{ 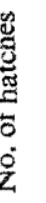 } & \multirow{2}{*}{$\begin{array}{l}\frac{5}{3} \\
\frac{0}{\overline{0}} \\
\frac{0}{0}\end{array}$} & \multirow[b]{2}{*}{$N^{*}$} & \multirow{2}{*}{$\begin{array}{l}\text { Length of } \\
\text { incubation } \\
\text { Mean } \\
\text { (SD) }\end{array}$} & \multicolumn{2}{|c|}{$\begin{array}{c}\text { Age } f \text { at training } \\
\text { Mean } \\
\text { (SD) }\end{array}$} & \multicolumn{2}{|c|}{$\begin{array}{l}\text { Age at first test } \\
\text { Mean } \\
(\mathrm{SD})\end{array}$} & \multicolumn{2}{|c|}{$\begin{array}{l}\text { Age at second test } \\
\text { Mean } \\
\text { (SD) }\end{array}$} & \multicolumn{2}{|c|}{$\begin{array}{c}\text { Training performance (s) } \\
\text { Median } \\
\text { (interquartile range) }\end{array}$} \\
\hline & & & & & P.H. & D.A. & P.H. & D.A. & P.H. & D.A. & Latency & Duration \\
\hline $1 \mathrm{a}$ & 4 & 100 & 29 & $\begin{array}{c}26: 16.6 \\
(3.7)\end{array}$ & $\begin{array}{l}23.3 \\
(1.5)\end{array}$ & $\begin{array}{c}27: 15.9 \\
(3.2)\end{array}$ & $\begin{array}{l}47.3 \\
(1.4)\end{array}$ & $\begin{array}{c}28: 15.9 \\
(3.6)\end{array}$ & $\begin{array}{l}59.3 \\
(1.3)\end{array}$ & $\begin{array}{c}29: 03.9 \\
(3.1)\end{array}$ & $\begin{array}{c}34 \\
(22-86)\end{array}$ & $\begin{array}{c}1066 \\
(670-1113)\end{array}$ \\
\hline $1 b$ & 4 & 97 & 30 & $\begin{array}{c}26: 20.7 \\
(4.4)\end{array}$ & $\begin{array}{l}23.2 \\
(1.4)\end{array}$ & $\begin{array}{c}27: 19.9 \\
(4.7)\end{array}$ & $\begin{array}{l}46.7 \\
(1.3)\end{array}$ & $\begin{array}{c}28: 19.4 \\
(4.5)\end{array}$ & $\begin{array}{l}58.8 \\
(1.5)\end{array}$ & $\begin{array}{c}29: 07.6 \\
(4.7)\end{array}$ & $\begin{array}{c}59 \\
(21-124)\end{array}$ & $\begin{array}{c}919 \\
(695-1056)\end{array}$ \\
\hline $1 \mathrm{c}$ & 3 & 97 & 33 & $\begin{array}{c}26: 15.5 \\
(4.7)\end{array}$ & $\begin{array}{l}23.8 \\
(1.6)\end{array}$ & $\begin{array}{c}27: 15.3 \\
(5.5)\end{array}$ & $\begin{array}{l}47.5 \\
(1.4)\end{array}$ & $\begin{array}{c}28: 14.9 \\
(5.5)\end{array}$ & $\begin{array}{l}59.4 \\
(1.6)\end{array}$ & $\begin{array}{c}29: 02.9 \\
(5.4)\end{array}$ & $\begin{array}{c}61 \\
(21-113)\end{array}$ & $\begin{array}{c}920 \\
(638-1055)\end{array}$ \\
\hline ld & 3 & 97 & 30 & $\begin{array}{c}26: 14.8 \\
(4.6)\end{array}$ & $\begin{array}{l}23.2 \\
(1.5)\end{array}$ & $\begin{array}{c}27: 13.7 \\
(5.2)\end{array}$ & $\begin{array}{l}46.8 \\
(1.5)\end{array}$ & $\begin{array}{c}28: 13.4 \\
(5.1)\end{array}$ & $\begin{array}{l}58.9 \\
(1.7)\end{array}$ & $\begin{array}{c}29: 01.5 \\
(5.3)\end{array}$ & $\begin{array}{c}45 \\
(28-83)\end{array}$ & $\begin{array}{c}894 \\
(726-1002)\end{array}$ \\
\hline
\end{tabular}

${ }^{*} N$ is the number of subjects tested in each group and does not include those subjects that did not follow during training. tAge is given as both post-hatching in hours (P.H.) and as developmental age in days and hours (D.A.). Standard deviations are given in hours in both cases. 


\section{Experiment 1}

If laboratory studies of imprinting have correctly identified the behavioural mechanism of visual species identification, then the expectation from such studies is as follows: if a duckling is briefly exposed to a member of its own species shortly after hatching and later faced with a choice between that individual and a member of a different species, it will show a preference for the familiar individual. To determine whether this expectation is correct, in the first experiment 125 Peking ducklings were given 20 min of training with a model of one of the three species of waterfowl (mallard, redhead, or pintail). Altogether, 122 subjects $(97.5 \%)$ followed during training. Subjects that followed were assigned to one of four experimental groups, as follows: Group la: Mallard versus Redhead; Group lb: Redhead versus Mallard; Group lc: Mallard versus Pintail; and Group ld: Pintail versus Mallard.

In each case, subjects were trained with the first-named of the two models identifying the group and then tested for evidence of a preference between that model and the second-named model identifying the group. Here and throughout this paper, initial capitals (e.g. Mallard) will be used when referring to the models used in the experiments, to avoid confusion with references to the actual biological species. Hatch, age, and training data arc presented in Table I.

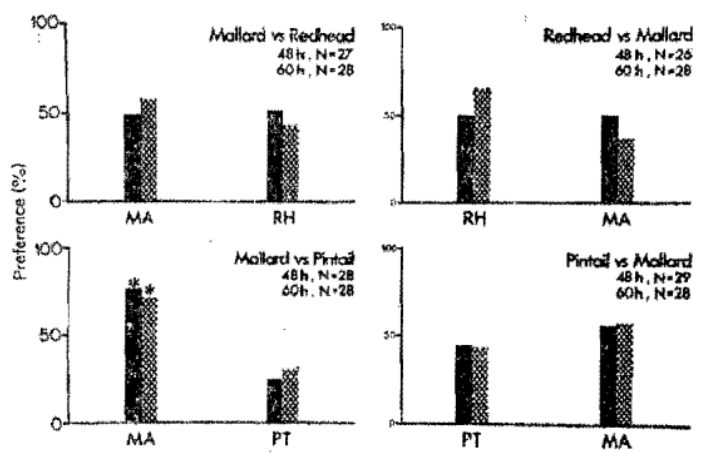

Fig. 3. Preferences of Peking subjects in each of the four groups of experiment 1 , after 20 min of training. Model on left side of each pair was training model. Solid bars : 48 -h test; hatched bars: 60 -h test. $\mathrm{MA}=$ Mallard; $\mathrm{RH}=$ Redhead; $\mathrm{PT}=$ Pintail. ${ }^{*} P<0.05$. Only those subjects that showed a preference are included in the data from each test; since not all subjects showed a preference on both tests, $N$ 's for the two tests may differ.

\section{Results}

As can be seen from the results in Fig. 3, in only one case (group lc: Mallard versus Pintail) was there any evidence of a preference for the familiar (trained) model over the unfamiliar model $(P<0.05)$. The analysis of the latency and duration scores from the 48-h test (Table II) supports this result. Subjects in group $1 \mathrm{c}$ had significantly shorter latencies $(z=3.00, P=0.002)$ and longer durations $(z=2.59, P<0.01)$ in their response to the Mallard (familiar) than to the Pintail (unfamiliar) model. In none of the other three groups was there any evidence of a preference for either model (in all cases, $P>0.3$ ). Stable individual preferences for the familiar model were only found in group lc $(P<0.01$; Table III); in the other three groups there was no stability of individual preferences $(P>0.5$; Table III).

\begin{tabular}{|c|c|c|c|c|}
\hline \multirow[b]{2}{*}{ Group } & \multicolumn{2}{|c|}{ Familiar model } & \multicolumn{2}{|c|}{ Unfamiliar model } \\
\hline & $\begin{array}{l}\text { Latency } \\
\text { (s) }\end{array}$ & $\underset{(s)}{\text { Duration }}$ & $\begin{array}{l}\text { Latency } \\
\text { (s) }\end{array}$ & $\underset{(s)}{\text { Duration }}$ \\
\hline $1 \mathrm{a}$ & $\begin{array}{c}70 \\
(21-600)\end{array}$ & $\begin{array}{c}95 \\
(0-501)\end{array}$ & $\begin{array}{c}69 \\
(20-600)\end{array}$ & $\begin{array}{c}195 \\
(0-493)\end{array}$ \\
\hline $1 \mathrm{~b}$ & $\begin{array}{c}195 \\
(38-600)\end{array}$ & $\begin{array}{l}183 \\
(0-445)\end{array}$ & $\begin{array}{c}38 \\
(17-600)\end{array}$ & $\begin{array}{c}164 \\
(0-522)\end{array}$ \\
\hline $1 \mathrm{c}$ & $\begin{array}{r}21^{* *} \\
(14-91)\end{array}$ & $\begin{array}{c}336 * * \\
(80-498)\end{array}$ & $\begin{array}{c}362 \\
(66-600)\end{array}$ & $\begin{array}{c}23 \\
(0-248)\end{array}$ \\
\hline $1 d$ & $\begin{array}{c}91 \\
(20-600)\end{array}$ & $\begin{array}{l}137 \\
(0-494)\end{array}$ & $\begin{array}{c}70 \\
(20-600)\end{array}$ & $\begin{array}{c}223 \\
(0-535)\end{array}$ \\
\hline
\end{tabular}

${ }^{* *} P<0.01$ (familiar versus unfamiliar model). 
Analysis of the latency and duration scores of those subjects that showed individual preferences on the first test revealed no evidence of a difference in either latency or duration of response to either preferred model. (Since we never found a significant difference in latency or duration scores between subjects that preferred one or the other model in any of the experiments, to save space we have not reported those results here. If desired, those data are available from the authors.)

Table III. Stability of Preferences shown by Individual Subjects in Experiments 1, 2, and 4

\begin{tabular}{lccccccc}
\hline \multicolumn{1}{c}{$\begin{array}{c}\text { Models } \\
\text { Familiar-Unfamiliar } \\
\text { (F-U) }\end{array}$} & $N$ & $F / F$ & $U / U$ & $U / F$ & $F / U$ & $P \dagger$ \\
& & & & & & \\
\hline Experiment 1 (Peking subjects) & 26 & 6 & 4 & 9 & 7 & $>0.7$ \\
Group 1a: Mallard-Redhead & 25 & 8 & 4 & 8 & 5 & $>0.5$ \\
Group 1b: Redhead-Mallard & 23 & 13 & 2 & 4 & 4 & $<0.01$ \\
Group 1c: Mallard-Pintail & 28 & 5 & 9 & 7 & 7 & $>0.5$ \\
Group 1d: Pintail-Mallard & & & & & & \\
Experiment 2 (Peking subjects) & 28 & 27 & 0 & 0 & 1 & $<0.001$ \\
Group 2a: Mallard-Red Box & 26 & 23 & 1 & 0 & 2 & $<0.001$ \\
Group 2b: Red Box-Mallard & 15 & 13 & 0 & 0 & 2 & $<0.001$ \\
Group 2c: Red Box-Green Ball & 13 & 11 & 0 & 0 & 2 & $<0.001$ \\
Group 2d: Green Ball-Red Box & 13 & & & & & \\
Experiment 4 (Mallard subjects) & & & & & & \\
Group 4a: Mallard-Redhead & 17 & 6 & 4 & 2 & 5 & $>0.5$ \\
Group 4b: Mallard-Pintail & 24 & 13 & 2 & 4 & 5 & $<0.01$ \\
\hline
\end{tabular}

*Data from subjects that showed a preference in both $48-\mathrm{h}$ and $60-\mathrm{h}$ tests.

$\dagger P$-values of $\chi^{2}$ statistic based on null hypothesis of no stability of preference between test and re-test.

\section{Discussion}

Before discussing the largely negative results of experiment I, we must consider the possibility that the difference between these results and the expectation from conventional imprinting studies may be due not to the use of natural models but to an experimental design that, for some reason, is simply ineffective. That possibility was exam-tried in experiment 2; after summarizing it we will discuss the results of both experiments together.

\section{Experiment 2}

To determine whether imprinting could be demonstrated by using artificial pairs of models more typical of those used in previous imprinting studies, 99 Peking ducklings were trained with either the Mallard, Red Box, or Green Ball model (see Fig. 2). Altogether, 98 subjects (99\%) followed during training. Subjects that followed were a: signed to one of four experimental groups, as follows: Group 2a: Mallard versus Red Box; Group 2b: Red Box versus Mallard; Group 2c: Red Box versus Green Ball; and Group 2d: Green Ball versus Red Box.

Table IV. Hatch, Age, and Training Data for Peking Subjects given 20 min Training with Highly Artificial Models in Experiment 2

\begin{tabular}{|c|c|c|c|c|c|c|c|c|c|c|c|c|}
\hline \multirow{2}{*}{ 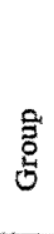 } & \multirow[t]{2}{*}{ 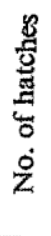 } & \multirow[t]{2}{*}{ 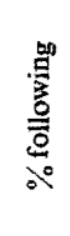 } & \multirow[t]{2}{*}{$N^{*}$} & \multirow[t]{2}{*}{$\begin{array}{l}\text { Length of } \\
\text { incubation } \\
\text { Mean } \\
\text { (SD) }\end{array}$} & \multicolumn{2}{|c|}{$\begin{array}{l}\text { Age } \dagger \text { at training } \\
\text { Mean } \\
\text { (sD) }\end{array}$} & \multicolumn{2}{|c|}{$\begin{array}{l}\text { Age at first test } \\
\text { Mean } \\
\text { (SD) }\end{array}$} & \multicolumn{2}{|c|}{$\begin{array}{l}\text { Age at second test } \\
\text { Mean } \\
\text { (SD) }\end{array}$} & \multicolumn{2}{|c|}{$\begin{array}{c}\text { Median } \\
\text { (interquartile range) }\end{array}$} \\
\hline & & & & & P.H. & D.A. & P.H. & D.A. & P.H. & D.A. & Latency & Duration \\
\hline $2 a$ & 2 & 100 & 30 & $\begin{array}{c}26: 14.5 \\
(5.6)\end{array}$ & $\begin{array}{l}23.8 \\
(2.1)\end{array}$ & $\begin{array}{c}27: 14.3 \\
(5.2)\end{array}$ & $\begin{array}{l}47.7 \\
(2.4)\end{array}$ & $\begin{array}{c}28: 14.3 \\
(5.0)\end{array}$ & $\begin{array}{l}59.6 \\
(2.4)\end{array}$ & $\begin{array}{c}29: 02.1 \\
(4.9)\end{array}$ & $\begin{array}{c}57 \\
(27-95)\end{array}$ & $\begin{array}{c}949 \\
(719-1080)\end{array}$ \\
\hline $2 b$ & 4 & 100 & 30 & $\begin{array}{l}26: 16.7 \\
(2.2)\end{array}$ & $\begin{array}{l}24.4 \\
(0.9)\end{array}$ & $\begin{array}{l}27: 17.1 \\
(1.9)\end{array}$ & $\begin{array}{l}47.9 \\
(1.1)\end{array}$ & $\begin{array}{c}28: 16.6 \\
(1.9)\end{array}$ & $\begin{array}{l}60.2 \\
(1.5)\end{array}$ & $\begin{array}{c}29: 04.9 \\
(1.8)\end{array}$ & $\begin{array}{c}68 \\
(50-207)\end{array}$ & $\begin{array}{c}698 \\
(367-911)\end{array}$ \\
\hline $2 c$ & 4 & 95 & 19 & $\begin{array}{c}26: 13.7 \\
(4.2)\end{array}$ & $\begin{array}{l}24.0 \\
(1.3)\end{array}$ & $\begin{array}{c}27: 13.7 \\
(4.4)\end{array}$ & $\begin{array}{l}47.5 \\
(1.6)\end{array}$ & $\begin{array}{c}28: 13.2 \\
(3.8)\end{array}$ & $\begin{array}{l}59.9 \\
(2.0)\end{array}$ & $\begin{array}{c}29: 01.6 \\
(4.2)\end{array}$ & $\begin{array}{c}50 \\
(27-82)\end{array}$ & $\begin{array}{c}879 \\
(785-1039)\end{array}$ \\
\hline $2 d$ & 3 & 100 & 19 & $\begin{array}{c}26: 12.6 \\
(5.8)\end{array}$ & $\begin{array}{l}24.6 \\
(0.7)\end{array}$ & $\begin{array}{c}27: 13.2 \\
(5.4)\end{array}$ & $\begin{array}{l}48.0 \\
(0.7)\end{array}$ & $\begin{array}{c}28: 12.6 \\
(5.4)\end{array}$ & $\begin{array}{l}59.7 \\
(0.9)\end{array}$ & $\begin{array}{c}29: 00.3 \\
(5.3)\end{array}$ & $\begin{array}{c}47 \\
(38-60)\end{array}$ & $\begin{array}{c}1035 \\
(753-1088)\end{array}$ \\
\hline
\end{tabular}

* $N$ is the number of subjects tested in each group and does not include those subjects that did not follow during training. †Age is given as both post-hatching in hours (P.H.) and as developmental age in days and hours (D.A.). Standard deviations are given in hours in both cases.

Once again, the first-named model in each group was the training model. Training and testing proceeded as in experiment 1 . Hatch, age, and training data are presented in Table IV. 


\section{Results}

The results of this experiment (Fig. 4) show clearly that our procedure was highly effective in producing a preference for the familiar model when preferences were assessed using pairs of models in which at least one model was of the artificial type generally used in studies of imprinting. All groups showed a significant preference $(P<0.01)$ for the familiar model on both first and second tests, and individual preferences were highly stable across tests in all four groups (in each case, $P<0.001$; see Table III). Analysis of the latency and duration scores supports this finding (Table V); latencies of response to the familiar model were significantly shorter $(P<0.02)$ and durations of response significantly longer $(P<0.02)$ in all groups.

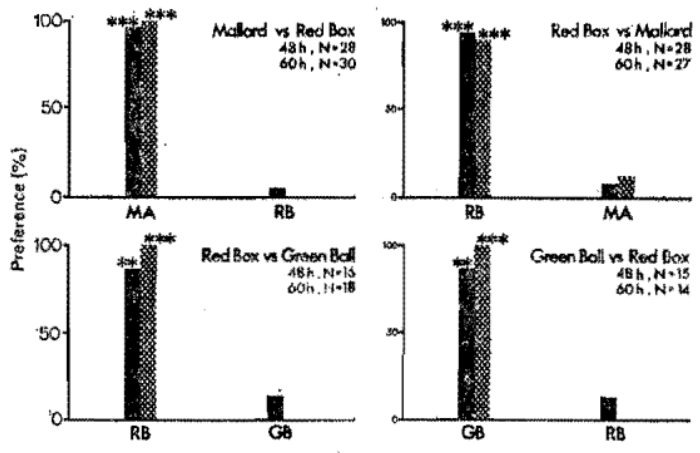

Fig, 4. Preferences of Peking subjects in each of the four groups of experiment 2 , after 20 min of training. MA $=$ mallard; $\mathrm{RB}=$ red box; $\mathrm{GB}=$ green ball. ${ }^{* *} P<0.01$ ${ }_{* * * *} P<0.001$. Other conventions as in Fig. 3 .

\begin{tabular}{|c|c|c|c|c|}
\hline \multirow[b]{2}{*}{ Group } & \multicolumn{2}{|c|}{ Familiar model } & \multicolumn{2}{|c|}{ Unfamiliar model } \\
\hline & $\begin{array}{l}\text { Latency } \\
\text { (s) }\end{array}$ & $\begin{array}{c}\text { Duration } \\
(\mathrm{s})\end{array}$ & $\begin{array}{l}\text { Latency } \\
\text { (s) }\end{array}$ & $\underset{(s)}{\text { Duration }}$ \\
\hline $2 a$ & $\begin{array}{c}29 * * * \\
(17-49)\end{array}$ & $\begin{array}{r}512 * * * \\
(403-556)\end{array}$ & $\begin{array}{l}600 \\
(-)\end{array}$ & $\stackrel{0}{(-)}$ \\
\hline $2 b$ & $\begin{array}{r}50^{* * * *} \\
(18-141)\end{array}$ & $\begin{array}{r}317 * * * \\
(202-467)\end{array}$ & $\begin{array}{c}600 \\
(131-600)\end{array}$ & $\begin{array}{c}0 \\
(0-23)\end{array}$ \\
\hline $2 c$ & $\begin{array}{r}21^{* *} \\
(16-79)\end{array}$ & $\begin{array}{c}419^{* *} \\
(236-490)\end{array}$ & $\begin{array}{c}600 \\
(559-600)\end{array}$ & $\stackrel{0}{(-)}$ \\
\hline $2 d$ & $\begin{array}{c}69^{*} \\
(18 \sim 551)\end{array}$ & $\begin{array}{c}334^{*} \\
(0-464)\end{array}$ & $\stackrel{600}{(-)}$ & $\stackrel{0}{(-)}$ \\
\hline
\end{tabular}

Familiar versus unfamiliar $P$ values: ${ }^{*} P<0.02$; **P $<0.01 ;{ }^{* * *} P<0.0001$.

\section{Discussion}

The results of experiments 1 and 2 reveal substantial differences between the preferences of birds tested with natural model pairs and those of birds tested with artificial pairs. The imprinting procedure we used was highly effective in producing strong, stable preferences among artificial pairs of models, as expected on the basis of previous studies of imprinting. However, it was much less effective in producing preferences among more natural models. In three of the four groups in experiment 1, no group preferences were found as a result of training, and individual preferences showed no stability between the first and second tests. It might be argued that this generally negative result was due to a greater perceptual saliency of the artificial objects in our apparatus; perhaps the natural models would be equally salient under more natural conditions so that exposure under such conditions would be more effective in producing a preference for the familiar model. This is not a compelling argument since one would expect a female duck to be less salient (i.e. better camouflaged) in her natural environment than in the laboratory, and it does not explain why subjects in group 2a (Mallard versus Red Box) showed a strong preference for the Mallard, whereas those in group la (Mallard versus Redhead) did not, even though both groups had the same training.

The latter finding could have been due to a greater responsiveness during training on the part of subjects in group 2a compared with those in group la. Such a difference in responsiveness would be revealed as either a shorter latency or a longer duration of following during training (Tables I and IV), but a Mann-Whitney $U$ test shows no significant difference in either the latency $(z=0.9, P=0.37)$ or the duration $(z=1.1, P=0.27)$ of following by the two groups.

In any experiment designed to investigate the effects of experience on subsequent preferences, the possible existence of naive preferences that are not the result of particular experiences must always be considered. Naive preferences cannot account for the main finding of experiments 1 and 2, since imprinting was always effective in experiment 2, regardless of which model was used to train the subjects. Consider, however, the difference between groups lc and 1d in experiment I: subjects trained with the Mallard and then tested for a preference 
between the Mallard and the Pintail (group 1c) showed a preference for the Mallard, whereas those trained with the Pintail and given the same choice test (group 1d) showed no preference. This result cannot be attributed to a greater responsiveness during training by subjects in group lc compared with those in group ld, since there was no significant difference in either latency $(z=0.6, . P=0.58)$ or duration $(z=0.7, P=0.48)$ of following between the two groups during training (Mann-Whitney $U$ test). However, the result might have been due to naive preferences among the three natural models, and this possibility was investigated in experiment 3 . A further possibility, that the ecological relationships among mallards, pintails, and redheads might account for the result of experiment 1 , will be discussed following experiment 4 , in which that result was replicated using a different strain of mallard ducklings.

\section{Experiment 3}

\section{Subjects}

Since subsequent experiments were conducted with both semi-wild mallard (experiment 4) and Peking (experiments 5 and 6) ducklings, subjects from both strains were tested for naive preferences in this experiment. In all, 82 Peking ducklings and 39 semi-wild mallard ducklings were tested in experiment 3.

Table VI. Hatch and Age Data for Peking and Semi-wild Mallard Subjects Tested for Naive Preferences in Experiment 3

\begin{tabular}{|c|c|c|c|c|c|c|c|}
\hline \multirow{2}{*}{$\begin{array}{l}\text { Subjects } \\
\text { (Age) }\end{array}$} & \multirow[b]{2}{*}{ Models } & \multirow{2}{*}{ 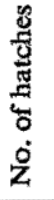 } & \multirow{2}{*}{$\begin{array}{l}\text { 㽞 } \\
\text { 总 } \\
\text { 总 } \\
\text { 용 }\end{array}$} & \multirow[b]{2}{*}{$N^{*}$} & \multirow{2}{*}{$\begin{array}{l}\text { Length of incubation } \\
\text { Mean } \\
\text { (SD) }\end{array}$} & \multicolumn{2}{|c|}{$\begin{array}{l}\text { Age† at testing } \\
\text { Mean } \\
\text { (sD) }\end{array}$} \\
\hline & & & & & & P.H. & D.A. \\
\hline $\begin{array}{l}\text { Peking } \\
(24 \mathrm{~h})\end{array}$ & $\begin{array}{l}\text { Mallard } \\
\text { vs } \\
\text { Redhead }\end{array}$ & 3 & 90 & 20 & $\begin{array}{c}26: 21.6 \\
(4.7)\end{array}$ & $\begin{array}{l}24.6 \\
(1.1)\end{array}$ & $\begin{array}{c}27: 22.2 \\
(5.0)\end{array}$ \\
\hline $\begin{array}{l}\text { Peking } \\
(48 \mathrm{~h})\end{array}$ & $\begin{array}{l}\text { Mallard } \\
\text { vs } \\
\text { Redhead }\end{array}$ & 3 & 92 & 24 & $\begin{array}{c}26: 17.6 \\
(5.8)\end{array}$ & $\begin{array}{l}47.6 \\
(0.9)\end{array}$ & $\begin{array}{c}28: 17.3 \\
(5.8)\end{array}$ \\
\hline $\begin{array}{l}\text { Peking } \\
(24 \mathrm{~h})\end{array}$ & $\begin{array}{l}\text { Mallard } \\
\text { vs } \\
\text { Pintail }\end{array}$ & 5 & 95 & 19 & $\begin{array}{c}26: 22.0 \\
(1.4)\end{array}$ & $\begin{array}{l}23.7 \\
(1.1)\end{array}$ & $\begin{array}{c}27: 21.7 \\
(1.3)\end{array}$ \\
\hline $\begin{array}{l}\text { Peking } \\
(48 \text { h) }\end{array}$ & $\begin{array}{l}\text { Mallard } \\
\text { vs } \\
\text { Pintail }\end{array}$ & 3 & 89 & 19 & $\begin{array}{c}26: 18.4 \\
(3.7)\end{array}$ & $\begin{array}{l}47.8 \\
(0.9)\end{array}$ & $\begin{array}{c}28: 18.3 \\
(4.3)\end{array}$ \\
\hline $\begin{array}{l}\text { Mallard } \\
(24 \mathrm{~h})\end{array}$ & $\begin{array}{l}\text { Mallard } \\
\text { vs } \\
\text { Redhead }\end{array}$ & 2 & 85 & 20 & $\begin{array}{c}25: 13.0 \\
(6.2)\end{array}$ & $\begin{array}{l}24.8 \\
(0.9)\end{array}$ & $\begin{array}{c}26: 13.8 \\
(6.4)\end{array}$ \\
\hline $\begin{array}{l}\text { Mallard } \\
(24 \mathrm{~h})\end{array}$ & $\begin{array}{l}\text { Mallard } \\
\text { vs } \\
\text { Pintail }\end{array}$ & 2 & 95 & 19 & $\begin{array}{c}25: 12.5 \\
(2.2)\end{array}$ & $\begin{array}{r}25.5 \\
(1.1)\end{array}$ & $\begin{array}{c}26: 14.0 \\
(1.5)\end{array}$ \\
\hline
\end{tabular}

${ }^{*} N$ is number of subjects actually tested, whether or not they responded. For number responding, see Fig. 5.

†Age is given as both posthatching in hours (P.H.) and as developmental age in days and hours (D.A.).

\section{Procedure}

Standard deviations are given in hours in both cases.

Naive preferences between the Mallard and Redhead models and between the Mallard and Pintail models were assessed for both Peking and semi-wild mallard ducklings by means of a simultaneous approach test at either 24 $\mathrm{h}$ or $48 \mathrm{~h}$ after hatching. Approach tests rather than following tests were used in this experiment because pilot work showed that naive ducklings often follow the first model that moves past them at the start of the test, so that tests with moving models would have produced results biased by a starting-position preference. The two models were therefore suspended from opposite ends of the T-bar and positioned in the centres of the elliptical approach areas marked on either side of the arena (Fig. 1). Because the ducklings show very little responsiveness to stationary silent models, the same recording of the mallard maternal call was played through the fixed loudspeakers adjacent to each model (see General Method for details). This raised the percentage of subjects responding in each group to about $91 \%$ (see Table VI), while providing no auditory basis for discrimination between the models (sec p. 1085). Each subject was tested only once, at either $24 \mathrm{~h}$ or $48 \mathrm{~h}$ after hatching. 


\section{Results}

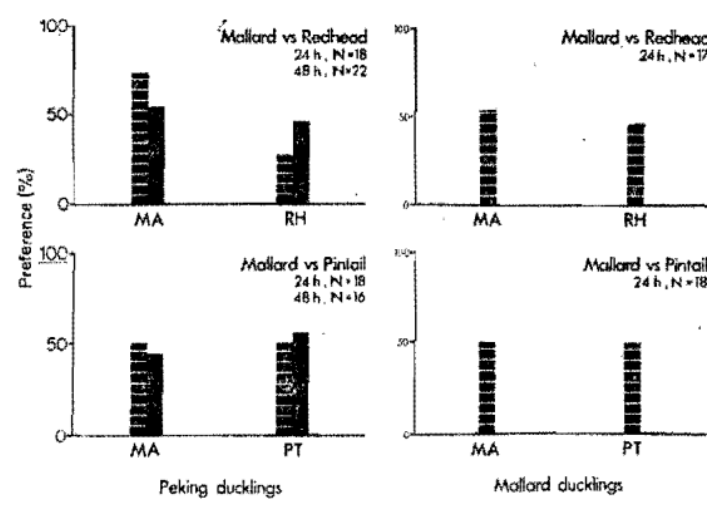

Fig. 5. Preferences of Peking (left) and semi-wild mallard (right) subjects in the naive preference tests in experiment 3. Each subject was tested only once, rather than twice as in experiments 1 and 2 . Broken bars: 24 -h test; solid bars: 48-h test. Other conventions as in Fig. 3.

The results of this experiment (Fig. 5) show no evidence of any naive preference among the Peking or semiwild mallard ducklings for either of the two natural model pairs at either of the ages tested, Analysis of the latency and duration data by means of the Wilcoxon test supports this finding with only one exception: at $24 \mathrm{~h}$ after hatching, Peking ducklings have significantly longer durations of approach to the Mallard than to the Redhead model $(z=2.29, P=0.02$; see Table VII).

Table VII. Latency and Duration of Response by All Naive Subjects to Both Models in Experinent 3 (Median and Interquartile Range)

\begin{tabular}{|c|c|c|c|c|c|}
\hline \multirow[b]{2}{*}{$\begin{array}{c}\text { Subjects } \\
\text { (Age) }\end{array}$} & \multirow[b]{2}{*}{$\begin{array}{l}\text { Models } \\
\text { (A vs B) }\end{array}$} & \multicolumn{2}{|c|}{ Model A } & \multicolumn{2}{|c|}{ Model B } \\
\hline & & $\begin{array}{l}\text { Latency } \\
\text { (s) }\end{array}$ & $\begin{array}{l}\text { Duration } \\
\text { (s) }\end{array}$ & $\begin{array}{l}\text { Latency } \\
\text { (s) }\end{array}$ & $\begin{array}{l}\text { Duration } \\
\text { (s) }\end{array}$ \\
\hline $\begin{array}{l}\text { Peking } \\
(24 \mathrm{~h})\end{array}$ & Mallard vs Redhead & $\begin{array}{c}76 \\
(46-600)\end{array}$ & $\begin{array}{c}449^{*} \\
(0-551)\end{array}$ & $\begin{array}{c}600 \\
(363-600)\end{array}$ & $\begin{array}{c}0 \\
(0-135)\end{array}$ \\
\hline $\begin{array}{l}\text { Peking } \\
(48 \mathrm{~h})\end{array}$ & Mallard vs Redhead & $\begin{array}{c}185 \\
(28-600)\end{array}$ & $\begin{array}{c}70 \\
(0-436)\end{array}$ & $\begin{array}{c}304 \\
(69-600)\end{array}$ & $\begin{array}{c}49 \\
(0-382)\end{array}$ \\
\hline $\begin{array}{l}\text { Peking } \\
(24 \mathrm{~h})\end{array}$ & Mallard vs Pintail & $\begin{array}{c}600 \\
(50-600)\end{array}$ & $\begin{array}{c}0 \\
(0-479)\end{array}$ & $\begin{array}{c}600 \\
(44-600)\end{array}$ & $\begin{array}{c}0 \\
(0-543)\end{array}$ \\
\hline $\begin{array}{l}\text { Peking } \\
(48 \mathrm{~h})\end{array}$ & Mallard ys Pintail & $\begin{array}{c}600 \\
(37-600)\end{array}$ & $\begin{array}{c}0 \\
(0-365)\end{array}$ & $\begin{array}{c}328 \\
(34-600)\end{array}$ & $\begin{array}{c}15 \\
(0-476)\end{array}$ \\
\hline $\begin{array}{l}\text { Mallard } \\
(24 \text { h) }\end{array}$ & Mallard vs Redhead & $\begin{array}{c}514 \\
(47-600)\end{array}$ & $\begin{array}{c}7 \\
(0-518)\end{array}$ & $\begin{array}{c}600 \\
(100-600)\end{array}$ & $\begin{array}{c}0 \\
(0-462)\end{array}$ \\
\hline $\begin{array}{l}\text { Mallard } \\
(24 \mathrm{~h})\end{array}$ & Mallard vs Pintail & $\begin{array}{c}600 \\
(33-600)\end{array}$ & $\begin{array}{c}0 \\
(0-320)\end{array}$ & $\begin{array}{c}600 \\
(40-600)\end{array}$ & $\begin{array}{c}0 \\
(0-421)\end{array}$ \\
\hline
\end{tabular}

\section{Discussion}

$* P=0.02$ (Model $\mathrm{A}>$ Model $\mathrm{B})$.

The lack of any clear-cut naive preferences among the subjects with regard to the two natural pairs of imprinting models makes it difficult to sustain an argument that the result from group 1c in experiment 1 was due to a naive preference for the Mallard compared with the Pintail model. It is possible that very subtle naive preferences among the models do exist and interact with exposure to the models in complex ways but that our technique is not sufficiently sensitive to detect them. It might be, on the other hand, that the result was simply due to chance (an inherently unsatisfying explanation), but data to be presented below in experiment 4 make that an unlikely possibility.

Since experiment 3 failed to support the existence of naive preferences in our subjects, we simplified the design of subsequent experiments and only trained subjects with the Mallard model before administering preference tests.

\section{Experiment 4}

The remaining experiments in this study concern the principal finding of experiments 1 and 2: the very much 
less pronounced preferences that are seen among natural rather than artificial pairs of models. The first question to be addressed is whether this finding might be a result of domestication. Since maintaining a strong motheroffspring bond is presumably not so important for survival in domesticated as in wild strains of waterfowl, one might argue that many generations of domestication have reduced the 'imprintability' of Peking ducklings in comparison with wild mallard strains. Thus, while imprinted Peking ducklings still respond to the large visual differences between artificial pairs of models (experiment 2), they do not respond to the subtle differences between more natural pairs (experiment 1). Recent experiments with domesticated strains of Norway rats (Rattus norvegicus; Boice 1972) and mallard ducks (Miller 1977b) have revealed that the behavioural effects of domestication may have been overestimated by some authors (e.g. Lorenz 1935/1937, 1940, 1954/1971). In previous work, Gottlieb $(1961,1971)$ has shown, using techniques very similar to those employed here, that the response of Peking ducklings to the species-typical maternal call is just as specific as that of wild mallard ducklings, and that Pekings are no less 'imprintable' than wild mallards. These findings weaken the prima facie appeal of a domestication hypothesis to account for the results of experiment 1, although they do not, of course, disprove it.

To test the domestication hypothesis, 56 semi-wild mallard ducklings (game-farm female $\mathrm{X}$ wild male) were given 20 min training with the Mallard model. Fifty-five subjects (98\%) followed and these were assigned to two experimental groups, as follows: Group 4a: Mallard versus Redhead; and Group 4b : Mallard versus Pintail. Nomenclature of groups follows that of experiment 1 . Hatch, age, and training data are presented in Table VIII.

Table VII. Hatch, Age, and Training Data for All Subjects in Experiments 4, 5, and 6

\begin{tabular}{|c|c|c|c|c|c|c|c|c|c|c|c|c|}
\hline & \multirow{2}{*}{ 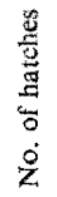 } & \multirow{2}{*}{ 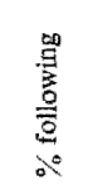 } & \multirow{2}{*}{\multicolumn{2}{|c|}{$\begin{array}{l}\text { Length of incubation } \\
N^{*} \quad \begin{array}{c}\text { Mean } \\
\text { (SD) }\end{array}\end{array}$}} & \multicolumn{2}{|c|}{$\begin{array}{l}\text { Age } \dagger \text { at training } \\
\text { Mean } \\
\text { (SD) }\end{array}$} & \multicolumn{2}{|c|}{$\begin{array}{l}\text { Age at first test } \\
\text { Mean } \\
\text { (SD) }\end{array}$} & \multicolumn{2}{|c|}{$\begin{array}{l}\text { Age at second test } \\
\text { Mean } \\
\text { (SD) }\end{array}$} & \multicolumn{2}{|c|}{$\begin{array}{c}\text { Training performance (s) } \\
\text { Median } \\
\text { (interquartile range) }\end{array}$} \\
\hline & & & & & P.H. & D.A. & P.H. & D.A. & P.H. & D.A. & Latency & Duration \\
\hline \multicolumn{2}{|c|}{$\begin{array}{l}\text { Experiment 4: } \\
\text { Group 4a }\end{array}$} & Semi-1 & ${ }_{28}$ & $\begin{array}{l}\text { ard subjects, } 20 \mathrm{~m} \\
25: 06.6 \\
\quad(3.9)\end{array}$ & $\begin{array}{l}\text { trainin } \\
22.6 \\
(1.6)\end{array}$ & $\begin{array}{c}26: 05.2 \\
(4.9)\end{array}$ & $\begin{array}{l}46.7 \\
(2.0)\end{array}$ & $\begin{array}{c}27: 05.3 \\
(4.8)\end{array}$ & $\begin{array}{r}59.0 \\
(1.8)\end{array}$ & $\begin{array}{c}27: 17.7 \\
(4.2)\end{array}$ & $\begin{array}{c}27 \\
(22-49)\end{array}$ & $\begin{array}{c}1107 \\
(904-1150)\end{array}$ \\
\hline Group $4 b$ & 3 & 100 & 27 & $\begin{array}{c}25: 05.4 \\
(3.8)\end{array}$ & $\begin{array}{l}24.5 \\
(0.9)\end{array}$ & $\begin{array}{c}26: 05.9 \\
(4.2)\end{array}$ & $\begin{array}{l}48.2 \\
(0.9)\end{array}$ & $\begin{array}{c}27: 05.7 \\
(4.0)\end{array}$ & $\begin{array}{l}60.4 \\
(0.8)\end{array}$ & $\begin{array}{c}27: 17.6 \\
(3.8)\end{array}$ & $\begin{array}{c}31 \\
(20-43)\end{array}$ & $\begin{array}{c}1092 \\
(912-1156)\end{array}$ \\
\hline Experiment & $5: 1$ & $\begin{array}{l}\text { Pekins } \\
100\end{array}$ & $\operatorname{subj}_{15}$ & $\begin{array}{c}24 \text { h passive exp } \\
26: 17.8 \\
(3.2)\end{array}$ & $\begin{array}{l}\text { sure } \\
26.2 \\
(2.1)\end{array}$ & $\begin{array}{c}27: 20.0 \\
(3.9)\end{array}$ & $\begin{array}{l}49.4 \\
(2.1)\end{array}$ & $\begin{array}{c}28: 19.2 \\
(3.9)\end{array}$ & $\begin{array}{l}61.1 \\
(2.4)\end{array}$ & $\begin{array}{c}29: 07.0 \\
(3.9)\end{array}$ & $\begin{array}{c}40 \\
(21-84)\end{array}$ & $\begin{array}{c}931 \\
(587-1048)\end{array}$ \\
\hline Experiment & $6: 1$ & $\begin{array}{l}\text { Peking } \\
100\end{array}$ & $\begin{array}{l}\text { subj } \\
14\end{array}$ & $\begin{array}{c}2 \mathrm{~h} \text { active traini } \\
26: 18.1 \\
(3.2)\end{array}$ & $\begin{array}{r}24.3 \\
(0.6)\end{array}$ & $\begin{array}{c}27: 18.4 \\
(3.3)\end{array}$ & $\begin{array}{l}48.3 \\
(1.1)\end{array}$ & $\begin{array}{c}28: 18.4 \\
(3.3)\end{array}$ & $\begin{array}{l}60.3 \\
(1.7)\end{array}$ & $\begin{array}{c}29: 06.4 \\
(3.9)\end{array}$ & $\begin{array}{c}60 \\
(38-87)\end{array}$ & $\begin{array}{c}508 \\
(410-939)\end{array}$ \\
\hline
\end{tabular}

*, $†$ See Table $I$. $\ddagger$ Training data are reported for the first 20 -min training period only (see Procedure).

\section{Results}

Semi-wild mallard ducklings trained with the Mallard and tested with the Mallard versus Redhead models (group 4a) showed no preference for either model, whereas those given the same training and tested with the Mallard versus Pintail models (group 4b) showed a significant preference for the Mallard model $(P<0.05$; see Fig. 6). The analysis of the latency and duration scores (Table IX) supports these results. in group 4a, neither latency $(z 1.33, P-0.18)$ nor duration $(z=1.41, . P=0,16)$ scores differed between the two models; in group $4 \mathrm{~b}$, subjects followed the Mallard model with a shorter latency $(z=1.92, P=0.054)$ and a longer duration $(z=$ $2.02, P=0.04)$ than they did the Pintail model. As in experiment 1 , stable individual preferences in semi-wild mallards were only found among those subjects tested with the Mallard and Pintail models $(P<0.01)$ and 001 among those tested with the Mallard and Redhead models $(P>0.5$; Table III $)$.

\section{Discussion}

The results of experiment 4 with semi-wild mallard ducklings parallel those of experiment 1 with Peking ducklings. In neither experiment did subjects trained with the Mallard model show a preference between the Mallard and Redhead models, whereas in both experiments similarly trained subjects preferred the Mallard to the Pintail model (compare Figs 3 and 6). Thus domestication cannot be advanced as an explanation for the 
largely negative results of experiment 1 , and other reasons for these results must be sought. The results of experiment 4 also suggest that the asymmetry of the results from groups lc and ld was not simply a statistical artifact, since the result from group lc was replicated in this experiment using three separate hatches from a genetically distinct (i.e. semi-wild) strain.

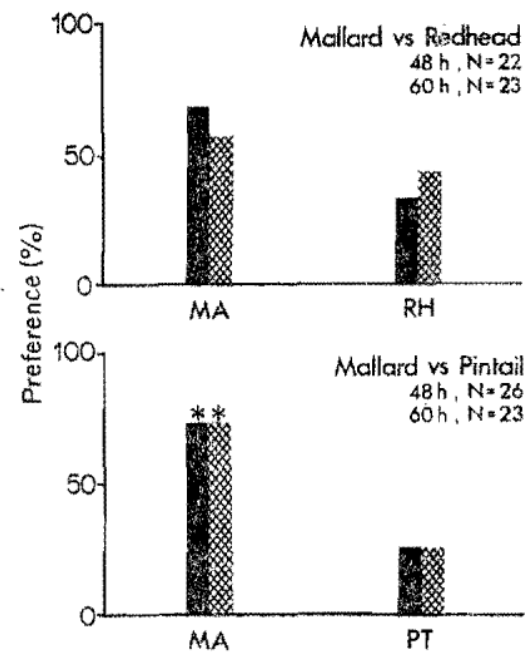

Fig. 6. Preferences of semi-wild mallard subjects in the two groups of experiment 4 , after $20 \mathrm{~min}$ training.

$* P<0.05$. Other conventions as in Fig. 3 .

An evolutionary hypothesis to account for these results may be based on the fact that the nesting ecology of mallards is more similar to that of pintails than to that of redheads (Beat 1951; Johnsgard 1975). Redheads typically nest in emergent vegetation over water and are rarely found nesting more than $50 \mathrm{~m}$ from open water, whereas mallards and pintails select more terrestrial nest sites, up to $400 \mathrm{~m}$ from water. Furthermore, mallards and pintails are among the earliest of the Anatidae to return to their: breeding grounds, the spring migration occurring as early as February, whereas redheads return later in the spring (Bent 1951). It is possible, therefore, that mallard ducklings encounter pintail hens and their broods more frequently than they encounter redhead hens, so that the ability to acquire a preference for mallards over pintails might be of greater selective advantage than the ability to acquire a preference for mallards over redheads. The fact that a preference in the MallardPintail test could only be demonstrated when the subjects were trained with the Mallard model (compare groups lc and ld) might similarly he explained by the fact that social attachments by mallard ducklings are normally formed to mallard hens, not to pintails. However, we must then explain the fact that a preference was readily formed for a completely artificial object (the red box) even when the other test model was the Mallard (experiment 2).

While this ecological hypothesis is an attractive one that hears further investigation, it should be pointed out that nest-site selection may not be the most important factor in determining the selection pressures acting on preference acquisition in ducklings. None of these species remains at the nest site for long after hatching, and little is known of the frequency with which mallard ducklings encounter broods of different species during the post-exodus period. Further information on the ecology of mallard broods, in addition to laboratory experiments, will be required before such hypotheses can be properly evaluated. We will return to this and related points in the General Discussion at the end of this paper.

Of course, we recognize that the above hypothesis does not address the question of the mechanisms whereby visually imprinting ducklings are able to distinguish between mallard and pintail hens, but not between mallard and redhead hens. That question is supplementary to the question of how those mechanisms may have evolved, and requires a different kind of analysis.

\section{Experiment 5}

In this and the following experiment we pursued the finding of experiment 1 that training ducklings with the Mallard model did not produce a preference for the Mallard over the Redhead model (group la). A likely explanation for that result is that 20 min of training is insufficient to permit a duckling subsequently to 
distinguish two closely similar natural models from one another. It has frequently been suggested (e.g. Bateson $1963,1966,1972)$ that whereas initial social preferences $m_{y}$ formed very rapidly, refinement and consolidation of those preferences continues for some time, possibly for days. Thus, a brief exposure may be sufficient to induce a preference for the familiar model over one that is greatly different in appearance, but further experience is necessary before more subtle differences (such as those that distinguish natural species from one another) can be discriminated.

\begin{tabular}{|c|c|c|c|c|}
\hline & \multicolumn{2}{|c|}{ Familiar model } & \multicolumn{2}{|c|}{ Unfamiliar model } \\
\hline & $\begin{array}{l}\text { Latency } \\
\text { (s) }\end{array}$ & $\begin{array}{l}\text { Duration } \\
\text { (s) }\end{array}$ & $\begin{array}{l}\text { Latency } \\
\text { (s) }\end{array}$ & $\begin{array}{l}\text { Duration } \\
\text { (s) }\end{array}$ \\
\hline $\begin{array}{c}\text { Experiment 4: } \\
\text { Group 4a } \\
\text { Group 4b }\end{array}$ & $\begin{array}{c}\text { Semi-wild mallard sub } \\
38 \\
(18-600) \\
20 \dagger \\
(13-148)\end{array}$ & $\begin{array}{c}20 \text { min trair } \\
220 \\
(0-518) \\
351^{*} \\
(71-497)\end{array}$ & $\begin{array}{c}386 \\
(24-600) \\
465 \\
(23 \sim 600)\end{array}$ & $\begin{array}{c}47 \\
(0-265) \\
17 \\
(0-172)\end{array}$ \\
\hline Experiment 5: & $\begin{array}{c}\text { Peking subjects, } 24 \mathrm{~h} \mathrm{p} \\
180 \\
(85-262)\end{array}$ & $\begin{array}{c}\text { exposure } \\
40 \\
(9-127)\end{array}$ & $\begin{array}{c}103 \\
(48-295)\end{array}$ & $\begin{array}{c}102 \\
(10-383)\end{array}$ \\
\hline Experiment 6: & $\begin{array}{c}\text { Peking subjects, } 2 \mathrm{~h} \text { ac } \\
188 \\
(17-337)\end{array}$ & $\begin{array}{l}\text { raining } \\
341 \\
(36-532)\end{array}$ & $\begin{array}{c}147 \\
(20-600)\end{array}$ & $\begin{array}{c}60 \\
(0-345)\end{array}$ \\
\hline
\end{tabular}

The trouble with the length-of-exposure hypothesis is that, as stated, it is hard to disprove, because the experience supposedly required for discrimination of natural species differences is not specified. We might, however, rephrase the hypothesis in a testable form as follows: as the duckling obtains more experience with one model, it becomes progressively better able to distinguish it from closely similar models, including those of related species. This hypothesis predicts a parametric relationship that is amenable to testing.

In the first of these two experiments, we attempted to simulate the normal experience of the ducklings as closely as possible by 'brooding' them with the Mallard model for $24 \mathrm{~h}$. before the training trial, This experience corresponds to the period prior to the nest exodus when the ducklings remain in close contact with their mother and have the opportunity to learn some of her visual characteristics before she leads them from the nest (Bjarvall 1967; Miller \& Gottlieb 1978).

\section{Subjects}

Fifteen Peking ducklings, from three separate hatches, served as subjects. All subjects followed during training.

\section{Procedure}

Immediately after hatching, subjects were placed in groups of five in a large cardboard box $(35 \mathrm{x} 40 \mathrm{x} 75 \mathrm{~cm})$ in the centre of which the Mallard model was suspended, approximately $2 \mathrm{~cm}$ above the floor, parallel with the long axis of the box. Two $250-\mathrm{W}$ heat lamps maintained the temperature in the box at $31 \mathrm{C}$. The loudspeaker in the model was connected to a tape cassette player that played a continuous-loop recording of the mallard preexodus call, consisting of short bursts of one to three notes, with an interval between bursts of 12 to $55 \mathrm{~s}$ (mean $=25 \mathrm{~s})$. The subjects remained in the box with the model for a mean of $23.3 \mathrm{~h}(\mathrm{SD}=1.2 \mathrm{~h})$, during which the loop was played continuously. The subjects were checked periodically and their behaviour noted; generally they were awake and alert, peeking at the model or moving around in the box, although on some occasions one or more were found dozing. After $24 \mathrm{~h}$, the subjects were removed and placed in individual boxes in a brooder (see General Method). They were then given a 20-min training trial with the Mallard model, followed by 10-min choice tests at 48 and $60 \mathrm{~h}$ after hatching as described in General Method. All subjects were tested for a preference between the Mallard and Redhead models. Hatch, age, and training data are presented in Table VIII. 


\section{Results}

At neither 48 nor $60 \mathrm{~h}$ was there a preference for either the Mallard or the Redhead model (P > 0.05; see Fig. 7). Analysis of the latency and duration scores (Table IX) supports this result; no significant difference between the responses to the two models was found for either score $(\mathrm{P}>0.05)$.

\section{Discussion}

The results of this experiment lend no support to the hypothesis that additional experience is all that is required to establish a preference for the Mallard model in the Mallard versus Redhead test. If such an explanation were correct, then we would expect, after $24 \mathrm{~h}$ of passive exposure and $20 \mathrm{~min}$ of active following, to see at least a slight, even if non-significant, preference for the Mallard model. In fact, any such evidence for a slight preference points toward the unfamiliar model: of those ducklings showing a preference, slightly more than half preferred the Redhead in both the 48-h (8/13) and 60-h (6/11) tests (Fig. 7).

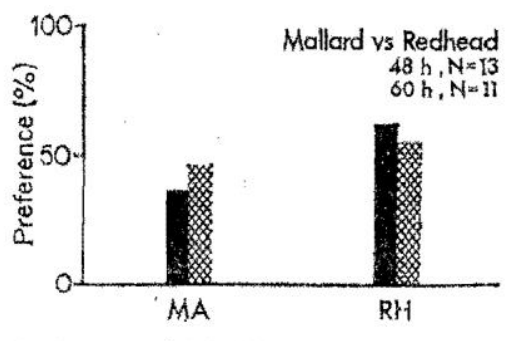

Fig. 7. Preferences of Peking subjects in experiment 5 , after $24 \mathrm{~h}$ of passive exposure to the Mallard model followed by 20 min training. Conventions as in Fig. 3.

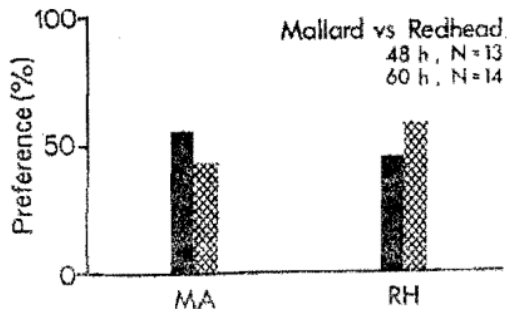

Fig. 8. Preference of Peking subjects in experiment 6 , after $2 \mathrm{~h}$ of training. Conventions as in Fig. 3.

Although the ducklings in this experiment received substantial exposure to the Mallard model, under circumstances that closely resemble those of the natural situation, this exposure was largely passive. It has been suggested by Hess $(1959,1973)$ that the strength of imprinting depends on the activity required of the subject to follow or approach the model: the so-called Law of Effort. While the evidence in favour of this view is not especially compelling (see Sluckin (1973), pp. 60-64, for a review), we considered it worthwhile to explore the possibility that more extensive active following might produce a preference for the Mallard in the Mallard versus Redhead test.

\section{Experiment 6}

\section{Subjects}

Fourteen Peking ducklings, from three separate hatches, served as subjects. All subjects followed during training.

\section{Procedure}

At $24 \mathrm{~h}$ after hatching, each subject received a single 125-min training trial with the Mallard model, consisting of four 20 min following periods alternating with three 15-min rest periods. During the periods of following, the recording of the mallard assembly call a as played through the speaker mounted inside the model. During the rest periods, the model was halted below a $250-\mathrm{W}$ heat lamp and the recording of the mallard pre-exodus call, described in the previous experiment, was played through the speaker. The latency and duration of following were recorded for the first 20-min following period only, for comparison with other experiments; during the remainder of the trial the subject's behaviour was observed although no quantitative data were collected. There was no evidence that fatigue resulted from the long training trial. At the end of the trial, the subject was placed in its individual box and returned to the brooder. Two 10-min choice tests were given at $48 \mathrm{~h}$ and at $60 \mathrm{~h}$ after hatching, respectively. Hatch, age, and training data are given in Table VIII.

\section{Results}

The results of experiment 6, shown in Fig 8, do not support the hypothesis that additional active following produces a preference for the familiar Mallard model. No such preference was found in either choice test, and the analysis of the latency and duration scores indicates no significant difference in the response to the two models ( $P>0.05$; see Table TX). 


\section{Discussion}

If our inability to demonstrate a preference for the familiar model using a natural model pair (Mallard versus Redhead) in experiment 1 were due solely to the length of the active training trial, then increasing the length of the trial by a factor of six, as in experiment 6 , would be expected to produce some preference for the Mallard model, even if not a statistically significant one. As with experiment 5, however, no such slight preference for the Mallard model can be discerned in the results from this experiment.

Therefore it must be concluded that, within the range of experience provided in the present study, neither length nor quality (whether active or passive) of exposure to the model can account for the failure to obtain evidence for imprinting using the natural Mallard and Redhead models. It will be recalled that the shortest exposure time used (20 min) was sufficient to produce a preference for the Mallard when testing involved either of the two highly artificial models (Red Box or Green Ball, experiment 2).

\section{General Discussion}

The results of this study provide grounds to question the frequently cited claim that visual species identification in precocial birds is accomplished solely, or primarily, by the process of imprinting. Although most previous research has assumed the truth of this claim and proceeded to elaborate the parametric details of the imprinting process, it now seems that the relationship between species identification and imprinting may bear closer examination. As remarked in the introduction, it is important to keep the problem of species identification, which young birds encounter and typically solve in the course of their normal ontogeny, conceptually separate from the process of imprinting, which is a laboratory paradigm hypothesized to be part of the solution to the species-identification problem. If, as seems reasonable, we define the problem of species identification to include making discriminations between waterfowl of different species, then our results provide grounds to question the hypothesis that imprinting, as conventionally formulated, is the means by which this problem is solved.

How, then, is the species-identification problem in fact solved under natural conditions? Our results do not provide an answer to this question, but they do allow us to suggest what may be a more appropriate approach to the problem. First of all, we would point out that understanding how an animal solves a problem in the course of development logically requires that we know what that problem is. It is not enough that we have a vague, intuitive account of what is involved in species identification. For example, 'making visual discriminations between familiar and unfamiliar objects' is, as we have shown, an inadequate formulation of the problem. Rather, the problem must be defined on the basis of naturalistic observations to determine the characteristics of the situations in which species identification typically occurs. Only when such accounts are available will it be possible to know the nature of the behavioural capabilities whose development we are to explain.

Despite the very large literature on the imprinting process, rather little information is at present available about the behaviour of duck broods under natural conditions. From the field studies that have been made, the ecological problems of species and individual identification for ducklings appear to involve a number of important aspects that are completely ignored by laboratory studies of imprinting. Whereas the young do frequently become separated from their mother, even shortly after hatching (Johnson 1974; Joyner 1977), it seems to be the mother rather than the young that takes the primary responsibility for ensuring brood cohesion. Several authors have reported that females attack strange young and drive them away from the brood (Alley \& Boyd 1950; Ramsay 1951; Joyner 1977), although the hen's ability to distinguish her own young from others of the same age and size appears to be limited (Alley \& Boyd 1950; Ramsay 1951). In addition, females of several species are reported to leave their broods for periods of up to an hour to feed by themselves (Stewart 1958, 1974; Beard 1964) and to relocate the brood on their return, even though it has moved in the interim.

Authors who have studied duck broods in the field are almost unanimous in reporting their impression that the hen's calls are more important than her appearance in controlling the ducklings' behaviour (e.g. Ramsay 1951; Gottlieb 1963; Bjarvall 1967; but see Joyner 1977). This impression has been repeatedly confirmed in controlled laboratory experiments (e.g. Gottlieb 1965, 1971, 1974; Impekoven 1976) and the developmental basis 
of species-specific auditory perception in one species, the mallard, has been the subject of intensive experimental study (e.g. Gottlieb 1979). Given the prepotency of the maternal call in eliciting approach by naive ducklings, it seems that under natural circumstances the problems of social attachment and species recognition may be solved largely in the auditory rather than the visual modality. In light of clear demonstrations that the maternal call is a potent factor in maintaining brood cohesion, it is curious that students of imprinting pay little attention to the role of species-specific auditory stimuli in the development of visual preferences. For example, Eiserer (1977, p. 153) remarks:

Moreover, it is possible that, with ducklings in a natural setting and with a natural mother, other sorts of stimulation besides visual motion (e.g. the mother's specific calls) might also innately elicit filial behavior. But in the laboratory setting, these species-specific signals are not ordinarily components of the arbitrarily selected imprinting objects that are typically used . . (emphasis added).

A few investigators have attempted to incorporate elements of the natural context into their studies of imprinting by using live adult females as imprinting models (see Shapiro 1980), but reports of aggressive behaviour by the (non-broody) models toward the subjects in some of these experiments decreases the reliance that can be placed on the results.

It is readily apparent, given even the limited data available in the literature, that the ecological context in which social attachments are formed by young ducklings is far more complex than the design of conventional imprinting experiments would imply. The roles in attachment formation of active maternal involvement, of species-typical auditory stimulation, and of other factors such as interactions with siblings are important problems that should not continue to be ignored. We do not mean to imply that the imprinting process plays no role in attachment formation; clearly the preference formed for the Mallard over the Pintail model in experiments 1 and 4 is best explained as a result of imprinting, perhaps of a selective nature. However, until other aspects of the ecological context are included in the analysis it will not be possible to specify in detail the role that imprinting plays in the formation of species-typical social attachments.

The results of the present study demonstrate one way in which an oversimplified approach to the speciesidentification problem may have led us to an incomplete account of the way in which this problem is solved by ducklings in the course of their development. In this final discussion we have indicated some additional aspects of the developmental context that might profitably be taken into account in future study. Gottlieb $(1973,1976)$ has previously suggested that in the experimental analysis of behavioural development, the natural context of development should be a more important consideration than is typically the case (see also Johnston \& Turvey 1980); our results lend further experimental support to this suggestion. Much current research on imprinting continues to be motivated by a non-ecological tradition of experimentation, despite the repudiation by a pioneer experimenter of his own early non-ecological approach to the problem (Hess [973). Our understanding of avian social development would be greatly enhanced by an increased willingness on the part of those working within this tradition to demonstrate the relevance of their results to the development of species-typical behaviour and social preferences.

\section{REFERENCES}

Alley, R. \& Boyd, H. 1950. Parent-young interaction in the coot (Fulica atra), Ibis, 92, 46-51.

Bateson, P. P. G. 1963. The Development of Filial and Avoidance Behaviour in the Domestic Chick. D. Phil. thesis, University of Cambridge.

Bateson, P. P. G. 1966. The characteristics and context of imprinting. Biol. Rev., 41, 177-220.

Bateson, P. P. G. 1972. The formation of social attachments in young birds. Proc. XV Intern. Ornith. Congr. (Leiden, 1970), 307-315.

Bateson, P. P. G. 1979. How do sensitive periods arise and what are they for? Anim. Behay., 27,470-486.

Beard, E. B. 1964. Duck brood behavior at the Seney National Wildlife Refuge. J. Wildl. Managmt, 28, 492521.

Bent, A. C. 1951. Life Histories of North American Wild Fowl, Volume 1. New York: Dover. 
Bjarvall, A. 1967. The critical period and the interval between hatching and exodus in mallard ducklings.

Behaviour, 28, 141-147.

Boice, R. 1972. Some behavioral effects of domestication in Norway rats, Behaviour, 42, 198-231.

Bronfenbrenner, U. 1977. Toward an experimental ecology of human development. Am. Psychol., 32, 513-531. Bronfenbrenner, U. 1979. The Ecology of Human Development. Cambridge, Mass.: Harvard University Press. Brunswik, E. 1952. The Conceptual Framework of Psychology. Chicago: University of Chicago Press.

Eiserer, L. A. 1977. Behavioral control by stimulus components of an imprinting object. Anim. Learn. Behav., 5, 153-160.

Gibson, J. J. 1966. The Senses Considered as Perceptual Systems. Boston: Houghton Mifflin.

Gibson, J. J. 1979. The Ecological Approach to Perception. Boston: Houghton Mifflin.

Gottlieb, G. 1961. The following-response and imprinting in wild and domestic ducklings of the same species.

Behaviour, 18, 205-223.

Gottlieb, G. 1963. A naturalistic study of imprinting in wood ducklings (Aix sponsa). J. comp. physiol. Psychol., $56,86-91$.

Gottlieb, G. 1965. Imprinting in relation to parental and species identification by avian neonates. J. comp. physiol. Psychol., 59, 345-356.

Gottlieb, G. 1971. Development of Species Identification in Birds, Chicago: University of Chicago Press. Gottlieb, G. 1973. Neglected developmental variables in the study of species identification in birds. Psycho!. Bull., 79,362-372.

Gottlieb, G. 1974. On the acoustic basis of species identification in wood ducklings (Aix sponsa), J. comp. physiol. Psycho!., 87, 1038-1048.

Gottlieb, G. 1976. The roles of experience in the development of behavior and the nervous system. In:

Development of Neural and Behavioral Specificity (Ed. by G. Gottlieb), pp. 25-54. New York: Academic Press.

Gottlieb, G. 1979. Development of species identification in ducklings: V. Perceptual differentiation in the embryo. J. comp. physiol. Psychol., 93, 831-854.

Heinroth, 0. 1911, Beitage zur Biologie, namentlich Ethologie und Psychologie der Anatiden. Proc. V Intern. Ornithol. Congr. (Berlin, 1910), 589-702.

Hess, E. 1959. The relationship between imprinting and motivation. In: Nebraska Symposium on Motivation (Ed. by M. R. Jones), pp. 44-77. Lincoln, Neb.: University of Nebraska Press.

Hess, E. 1973. Imprinting. New York: Van Nostrand Reinhold.

Impekoven, M. 1976. Responses of laughing gull chicks (Larus atricilla) to parental attraction- and alarm. calls, and effects of prenatal auditory experience on the responsiveness to such calls, Anim. Behay., 56,250-278. Johnsgard, P. A. 1975. Waterfowl of North America. Bloomington, Ind.: Indiana University Press. Johnson, T. W. 1974. A study of mottled duck broods in the Merritt Island National Wildlife Refuge. Wilson Bull., 86, 68-70.

Johnston, T. D. \& Turvey, M. T. 1980. A sketch of an ecological metatheory for theories of learning. In: The Psychology of Learning and Motivation, ol. 14 (Ed. by G. H. Bower), pp. 147-205. New York: Academic Press, Joyner, D. E. 1977. Behavior of ruddy duck broods in Utah. Auk, 94, 343-349.

Lorenz, K. Z. 1935. Der Kumpan in der Umwelt des Vogels. J. Ornithol., 83,137-213,289-413. (Translated: 1937. The companion in the bird's world. Auk, 54, 245-273.)

Lorenz, K. Z. 1940. Durch Domestikation verursachte Storungen arteigenen Verhaltens. Z. Angew. Psycho!. Char., 59,2-82.

Lorenz, K. Z. 1971. Psychology and phylogeny. In: Studies in Animal and Human Behaviour (Vol. 2) (Translated by R. Martin), pp. 196-245, Cambridge, Mass.: Harvard University Press. (Originally published 1954.)

McCall, R. B. 1977. Challenges to a science of developmental psychology. Child Devel., 48, 333-344.

Miller, D. B. 1977a. Roles of naturalistic observation in comparative psychology. Am. Psychol., 32, $211-219$. Miller, D. B. 1977b. Social displays of mallard ducks (Anas platyrhynchos): effects of domestication. J. comp. physiol. Psychol., 91,221-232.

Miller, D. B. \& Gottlieb, G. 1978. Maternal vocalizations of mallard ducks (Anas platyrhynchos). Behav., 26, 1178-1194.

Ramsay, A. 0. 1951. Familial recognition in domestic birds. Auk, 68,1-16. 
Shapiro, L. J. 1980. Species identification in birds: a review and synthesis. In: Species Identity and Attachment (Ed. by M. A. Roy), pp. 69-112, New York: Garland Press.

Sluckin, W. 1973. Imprinting and Early Learning. Chicago: Aldine.

Spalding, D. A. 1873. Instinct, with original observations on young animals. Macmillan's Mag., 27, $282-293$.

(Reprinted: 1954. Brit. J. Anim. Behav., 2, 2-11.)

Stewart, P. A. 1958. Local movements of wood ducks (Aix sponsa). Auk, 75, 157-168.

Stewart, P. A. 1974. Mother wood ducks feeding away from their broods. Bird Banding, 45, 58.

(Received 6 June 1980; revised 9 January 1981; MS. number: A2494) 